Article

\title{
"They Will Keep Seeing Young Women Murdered by Men. Enough Is Enough-We Have Seen too Many Women Lose Their Lives". Lessons for Professionals Working with Victims of 'Honour' Abuse and Violence
}

\author{
Reema Begum ${ }^{1}$, Roxanne Khan ${ }^{1, * \mathbb{D}}$, Gayle Brewer ${ }^{2}$ and Beth Hall ${ }^{1}$ \\ 1 School of Psychology, University of Central Lancashire, Preston PR1 2HE, UK; mitha741@gmail.com (R.B.); \\ BHall9@uclan.ac.uk (B.H.) \\ 2 School of Psychology, University of Liverpool, Liverpool L69 3BX, UK; gayle.brewer@liverpool.ac.uk \\ * Correspondence: rkhan2@uclan.ac.uk
}

Received: 12 March 2020; Accepted: 10 June 2020; Published: 1 July 2020

check for updates

\begin{abstract}
The brutal 'honour' killing of Banaz Mahmod, aged 20, is still one of the most prominent murder cases of this kind in Britain. This was due partly to its complexity as well as the poor police response to Banaz's pleas for help before her death-most notably, she reported her abuse on multiple occasions, forewarned them of her murder, and named her killers. This tragic case was a painful example of how professional agencies in the UK fail victims of so called 'honour' abuse and violence. Fifteen years on, support services are still naive about the people and communities most vulnerable to 'honour' abuse in Britain. More recently, campaigns to include Black, Asian, and other ethnic minority victims in the mainstream domestic abuse agenda have encouraged agencies to be culturally-competent in their support of 'honour' abuse victims, to redress previous failings. To facilitate this, this study conducted a focus group discussion with fourteen women (12 victim survivors and 2 support workers) recruited from a support organisation for ethnic minority women dealing with 'honour' abuse, to gain insight into their lived experiences. Interviews were analysed using interpretative phenomenological analysis. Three superordinate themes emerged, each with two sub-themes; vulnerability (sub-themes, fear of external organisations and racism); organisational and agency support (sub-themes, education and support from law enforcement), and rules and restrictions (sub-themes, immigration status and agency funding). These themes should be explored by professionals to better understand how to support female victims of 'honour' abuse and violence, without disparaging their culture.
\end{abstract}

Keywords: Black; Asian; minority ethnic women; domestic abuse; forced marriage; honour-based violence; harmful traditional practices; racism; South Asian women

\section{Introduction}

When Banaz Mahmod was murdered in 2006, she had already been to the police at least five times. In an interview room, the 20-year-old Londoner told an officer about her husband's abuse and the threats to her life. In a shaky video filmed on her boyfriend's phone while Mahmod was in hospital after her father made the first attempt on her life, she named the men that would murder her. Mahmod died weeks later in a so-called honor killing because she was perceived to have brought shame on her family. She had left her arranged marriage to have a relationship with a close friend... 
(Sophie Brown 2019, “What it's like to lose your sister in an honor killing")

South Asian and Arab communities in Britain tend to identify with cultural collectivism, and place great value on protecting family honour (or izzat) from shame (or sharam) (Gill 2008). Fewer than 3 million people in the UK are of South Asian (i.e., Indian, Pakistani or Bangladeshi) or Arab heritage, representing just $5.7 \%$ of the total population (Office for National Statistics 2019). Yet, victim data on so called 'honour' violence (which includes forced marriage) shows that those most at risk of this abuse in the UK are ethnic minority women of South Asian and Arab heritage (Dyer 2015; Her Majesty's Inspectorate of Constabulary (HMIC) 2015; Khan et al. 2018). In this qualitative study, we explored British Asian and Arab women's lived experiences of so called 'honour' abuse and violence, to gain insight into the personal barriers they face when seeking help, which have been found to be compounded by racial prejudice (Mason-Bish and Zempi 2019) and poor responses from support services (Idriss 2018).

\subsection{Collective Honour Cultures: Gender Roles}

Vandello (2016, p. 234) reflected that "Painting with broad strokes a picture of billions of people undoubtedly oversimplifies and, at worst, runs the risk of caricature and stereotyping. It is important to recognise nuance and variation, both across ... cultures and within." To echo this sentiment, while appreciating central and defining cultural features, the following review at times makes broad statements to capture generalised behaviour, yet any inference that culturally-bound practices universally define behaviour within specific ethnic communities is unintended.

Collectivist honour cultures emphasise the maintenance of strong bonds with both immediate and extended family (Khan 2018; Vandello 2016). Darwish and Huber (2003, p. 48) defined collectivism as a system in which " ... people feel they belong to larger in-groups or collectives which care for them in exchange for loyalty-and vice versa". Collectivist honour cultures are also patriarchal and are thus, characterised by differential and unequal gender roles (Rafferty 2013). Women, for example, are often constrained by the demands imposed on them by countless others (Vandello 2016). Their daily conduct and interactions may be monitored closely by family and friends as well as members of their local community (Khan 2018). Collectivist honour cultures tend to be religiously and socially conservative (Abu-Lughod 2016; Al Gharaibeh 2016; Lowe et al. 2018), and it is common for women's attire, behaviour and conduct to be openly scrutinised to judge whether their appearance and conduct aligns with social expectation (Cooney 2014). While females are expected to behave in a way that demonstrates purity, modesty, loyalty and passivity to male kin, males must act tough, dominant, and with authority over female relatives (Cohen and Nisbett 1994). Males are expected to keep their female counterparts in line, punishing them if they, or others, judge them to have behaved improperly (Cooney 2014; Vandello and Cohen 2003).

This cultural system is so powerful that it may override the emotional desire to love and protect family members and friends. It is not uncommon for loved ones to turn their backs on vulnerable girls and women, refusing to defend them or to offer them refuge (Khan 2018). Unlike other forms of domestic violence and child abuse, multiple and close family members-parents, siblings, uncles, aunts, cousins, nephews, in laws-become the harshest critics and cruellest of abusers (Aplin 2016; Bates 2018; Dyer 2015; Hague et al. 2013). In this cultural stranglehold, women are often judged at the whim of any number of observers-sometimes harshly and with extreme prejudice (Gengler et al. 2018). In this Catch-22 predicament, women can be treated with great contempt if others perceive them to have transgressed an 'acceptable' code of conduct, with or without evidence. In a harsh reality, it is near impossible for women to navigate their way through the rocky terrain of this patriarchal hierarchy, even if they move with extreme caution. Ultimately, it is a dual-purpose system designed to maintain the status quo-it is engineered to uphold men's dominance while subjugating women (Cooney 2014; Khan 2018). 


\subsection{Shame and Honour}

This social conditioning leads to women being shamed at any time and by anybody for behaving in a way that is subjectively deemed as socially undesirable. This charge of shame is serious and damning - it marks the woman accused as 'dishonourable' and this tarnishes not only her reputation but that of her male kin, her family, and the wider community (Dyer 2015; Hague et al. 2013). The powerful concept of honour (and dishonour) is the moral foundation of gender hierarchy in collectivist cultures (Abu-Lughod 2016). It also reflects and reinforces collectivism by emphasising the maintenance of strong family ties (Vandello 2016). This cultural context is important to understand as these norms underpin people's behaviours and beliefs about the treatment of women as well as how women perceive themselves. Cultural collectivism, for example, encourages individuals, families and communities to pressurise married women to comply with their husband's demands, support his decisions, and be faithful—despite his behaviour and her own feelings (Galanti 2003; Lowe et al. 2018).

\subsection{Health Impact}

Being judged while stripped of autonomy and agency, it is unsurprising that the physical and psychological impact on women in this context is substantial. Broadly, British South Asian women are considered to be an 'at risk' group for suicide (McKenzie et al. 2008), suicide attempts (Forte et al. 2018) and self-harm - cultural conflicts with family are the most common reported precipitating factor for suicide ideation (Hicks and Bhugra 2003; Husain et al. 2011). In countries of heritage, there is an equally bleak picture. Indian national crime data showed that in 95 percent of all rape cases, the rapist knew the victim (e.g., immediate family members, live-in partners, husbands, neighbours) (Sharma 2017). UNICEF (2014) reported that 42\% of girls in India had been sexually abused before 19 years, and that one fifth were forced to marry as children. Another stark finding is that nearly $40 \%$ of all female suicides globally occur in India (Patel et al. 2012) — a structural erosion of women attributed to forced or early marriage, male violence and patriarchal culture. Add to this mix that in countries of heritage, Pakistan is estimated to have the highest global rate of 'honour' killings (Fatima et al. 2017) while Britain is the 'honour' killing capital of Europe, with an estimated 12 murders each year (Dyer 2015). These women are at high risk of attempting to erase themselves, while being at risk of being erased by others.

\subsection{Barriers to Formal Help-Seeking}

The police force doesn't understand the family dynamics ... They don't understand the community ties and complicated relationships. I'm not saying they don't want to, but I'm saying until they actually learn to see the signs of danger, they can't help them. They will keep seeing young women murdered by men. Enough is enough-we have seen too many women lose their lives.

(Payzee Mahmod, sister of Banaz Mahmod, cited in Sophie Brown 2019: “What it's like to lose your sister in an honor killing")

Several features specific to 'honour' abuse and violence are likely to prevent women in the UK approaching professional agencies for help or support for their abuse. In particular, familial dynamics have been blamed for chronic underreporting by victims (Rafferty 2013). In a systematic review of 21 studies on domestic violence, women from communities in which family abuse is normalised were less likely to seek help, as were women with stronger patriarchal or conservative beliefs (Afrouz et al. 2018). Women may also be reluctant to seek formal help to protect their partner, preserve their relationship (Fugate et al. 2005), and to protect the family's honour and reputation (Afrouz et al. 2018). Indeed, a national household study in Pakistan found that out of 7897 women who had been physically abused, only 111 disclosed this to someone outside of their family (Andersson et al. 2010).

Lack of awareness of external support is also a barrier to formal help-seeking (Afrouz et al. 2018). Knowledge about financial and housing support is particularly salient as dependency is a significant 
barrier for help-seeking (Afrouz et al. 2018; dos Ventos Lopes Heimer 2019; Fugate et al. 2005; Raj and Silverman 2007). The belief that formal help is neither needed nor useful is another reason for domestic abuse victims not attempting to access services (Fugate et al. 2005). British Asian Muslim women may be particularly reluctant to involve outsiders in what they may consider to be a private family matter (Afrouz et al. 2018). In the context of leaving abusive relationships, in comparison to non-Muslim survivors of abuse: $37 \%$ more Muslim survivors believed that their culture prevented them from leaving, $40 \%$ more feared negative reactions from their community, and $27 \%$ feared reprisals from their husband's family (Ammar et al. 2013).

A range of external barriers to accessing help and support are also reported. These include immigration status (Chowbey 2016; Merchant 2000). With immigration, comes a loss of social support (Ahmad et al. 2009), and immigrants may not be sufficiently aware of their rights in their new resident country (Afrouz et al. 2018) or have access to appropriate interpreters where necessary (Idriss 2018). Furthermore, for women who have moved to the UK to join their husband, if the marriage ends within one year, she will not be able access state benefits, and may potentially face deportation (Burman and Chantler 2005). Thus, there is a need for legal support and information on rights relating not only to domestic abuse but also immigration (Raj and Silverman 2007). Another palpable barrier is when external agencies frame 'honour' abuse as a simply a cultural issue, distinct from other forms of domestic violence and outside of mainstream safeguarding (Khan and Hall 2020). This may impact on professional service providers, who may be reluctant to intervene or whose efforts to help might be restricted or constrained due to concerns of being seen as culturally insensitive (Eshareturi et al. 2014) or racist (Almeida and Dolan-Delvecchio 1999; Meetoo and Mirza 2010).

Efforts to raise awareness of ethnic minority victims' experiences of domestic abuse are reliant on continued and current research evidence, building on and strengthening existing knowledge to drive policy change (Khan et al. 2020). This study, therefore, conducted a focus group discussion to explore the lived experience of 'honour' abuse victims and survivors, after they had escaped from their abusive situation, and in recognition that they often suffer three-fold: the harm inflicted by their abusers, self-blame born out of being shamed and the poor response from mainstream support services. An additional layer of suffering occurs when they also experience racism or are overlooked by external organisations due to cultural ignorance or fear of being racist (Khan and Hall 2020).

\section{Materials and Methods}

Victim survivors of 'honour'-based abuse $(n=12)$ and support workers employed at a non-profit organisation for victims of 'honour'-based abuse $(n=2)$ were recruited via the Honour Abuse Research Matrix (HARM) network, based at the University of Central Lancashire. All participants were ethnic minority women, predominantly of Pakistani, Bangladeshi, and Arab heritage. All participants consented to take part in a focus group facilitated by the lead researcher and a member of the host (charitable) organisation. Open-ended questions were asked to prompt participants to share their experiences and contribute to the focus group discussion. The focus group lasted for $90 \mathrm{~min}$. Reflecting the sensitivity of the subject area and safety concerns, the session was not audio recorded. The lead researcher took extensive notes throughout the session. Similarly, though participants were no longer in immediate risk from their partner or family, demographic details were not taken to promote participant anonymity and protection.

Data were then analysed via Interpretative Phenomenological Analysis, an approach that adopts a phenomenological, hermeneutic, and idiographic perspective (Smith et al. 2009) which allows researchers to describe, interpret, and understand the lived experience of a group and the manner in which individuals make sense of that lived experience. Though interviews are more commonly used for Interpretative Phenomenological Analysis, a number of studies (e.g., De Visser and Smith 2007; Dunne and Quayle 2001; Flowers et al. 2003) have applied this analytic method to focus group data. Further, participants, particularly those from marginalised or minority groups, may benefit from focus groups rather than individual interviews (Race et al. 1994). Focus groups can provide a 
'safe space' (Madriz 2000) which encourages the sharing of experiences (Kitzinger 1995; Schatzman and Strauss 1973) and provides a forum for the empowerment of ethnic minority women who have experienced abuse.

During the analysis, the researcher repeatedly read and reviewed their notes to aid familiarisation and made a note of important areas. Following further readings, these notes were arranged into emergent themes. Finally, relationships between themes were identified and these were arranged into superordinate and sub-themes. This process was validated by discussions with co-authors. The project received ethical approval from the University of Central Lancashire Psychology and Social Work Ethics Committee, in following the code of ethics governed by the British Psychology Society. All participants provided their informed consent for inclusion and the research was conducted in accordance with the Declaration of Helsinki (1975).

\section{Results}

Three superordinate themes emerged from the focus group; vulnerability, organisational and agency support, and rules and restrictions. All quotations are from victim survivors of 'honour'-based abuse unless otherwise specified.

\subsection{Vulnerability}

Participants $(\mathrm{P})$ reported a range of issues that exacerbated the vulnerability they experienced in response to 'honour' abuse and violence. These issues included fear of external organisations and racism.

\subsubsection{Fear of External Organisations}

A minority of participants reported an initial fear of external organisations. This was often a consequence of deliberate deception by abusive partners or family members. For example, one participant reported "I had a friend who was from the police service and she helped me a lot at the beginning of the 3 years, she used to come and visit me often. But when she was here, my mother-in-law would take me into the kitchen and say if I tell her anything, she will report me to the police and send me to jail and that she will take my daughters from me. So out of fear I never said anything" (P5). This was endorsed by another participant whose mother-in-law had also misrepresented the police. "My family told me the same thing." (P13). Following direct contact with law enforcement, women typically recognised the deception, "The experience with the police was very good, at first I couldn't believe it. I just thought about what my mother-in-law had told me. I used to believe what she said was true about the police, that they would take me away and separate me from my children ... And the police officers were really lovely, they helped a lot and they didn't even give my daughters to my mother-in-law, they didn't let her anywhere near my daughters. Instead they gave my daughters to me." (P5).

\subsubsection{Racism}

Reflecting the complexity of issues experienced by victims of 'honour' abuse and violence, participants also reported racist abuse from the wider community. As explained by one woman, "First I was a prisoner of abuse from my in-laws and now I'm a prisoner and getting abused from the white community. Now that I've moved out, I am on my own-I'm free, but my children are still trapped inside the house. My daughter can't go out with her niqab on. They write slogans all over, pelting her with stones, and they throw eggs at my house. I'm suffering from diabetes, migraine, depression, stress and every time I step outside my house and walk on the street, I get shouted and sworn at by a white person." (P5). The impact of this racist abuse was acknowledged by agency support workers, who attempted to address this when accommodating women. One support worker commented "When you're applying for houses ... sometimes it doesn't show you a true reflection of the house and area. So when I apply on behalf of clients, I keep saying not to put Black and Minority Ethnic women in 
certain areas because now they become put in an area, where they face constant racism ... You want to think where your community is and that is really important." (P1).

\subsection{Organisational and Agency Support}

The value of the support provided by external agencies was clear, with women reporting that these agencies "basically gave me my life" (P9) and "helped me get my life back on track" (P7). In particular, women focused on the value of education and law enforcement.

\subsubsection{Education}

For example, women reported "[names agency] has helped me with education. They put me on courses to learn IT skills. Now they are helping me take lessons that can help me in the future with finding a job, which will help me become stable." (P6). Language based education was especially valued by these women, who explained they "They helped me with speaking English and learning the language. They helped me with my education. I'm doing maths and English classes." (P4) and "They helped me with English classes and supported me in doing other courses so I can get a job and a nice house." (P8).

\subsubsection{Support from Law Enforcement}

Despite initial concerns about law enforcement (see vulnerability theme) women typically reported positive experiences of law enforcement. One participant commented "The policewomen and support worker I got were really kind to me. At that time, I was very scared because for the first time, I was single... so my support worker would ring me all the time to see if I was okay and know my situation." (P10). Similarly, another woman stated "At that time I was very scared because it was happening for the first time and I became alone and single. I didn't know anyone. So, the police lady would ring me all the time to see if I was okay and know my situation before I had a support worker." (P11). However, confusion and bureaucracy were also evident. As one woman stated, "I even called the police and everybody was just sending me from place to place telling me that I should go to this place and I should go to that place, nobody was willing to stop and help me." (P3).

\subsection{Rules and Restrictions}

\subsubsection{Immigration Status}

Women were acutely aware of the importance of immigration status that impacted on both social capital and access to fundamental support. This had a dramatic impact on their experience of reporting their abuse to support services. As stated by one woman "One of the really important things is that agencies won't help you, if you haven't got access to public funds, and your immigration status is really, really important. At that time, nothing was right for me, like my immigration. This means that if you don't have the right immigration stamp in your passport, you can't always get the help you need. I couldn't get benefits and the problem was that I did have the right stamp, but it's just that I left and went back home [Pakistan] and because I had done that, I broke the ninety-day window. So, I had nowhere left to go, and it became a crisis." (P3). Consequently, charity-based support services had an important role in this field. One participant explained "My immigration status was not right-like my visa—and so my support worker helped me through it all. But it was a really long and painful process." (P4).

\subsubsection{Agency Funding}

Participants strongly endorsed the support provided by charitable support agencies. However, both support agency workers and abuse victims were aware of the limitations placed on this support. These issues were a result of restricted funding. One support worker explained "But there's a limit. We make difficult decisions and sometimes you have to make them, because [names agency] doesn't 
get funding unless I apply for it. For this to stay open, it's all down to me on a piece of paper and a funding application. Without the funding, there is cutting points as well as, waiting around for other agencies to do their part." (P1). One abuse victim explained that her own support had been limited as a result of these funding and workload issues "I have been a client at [names agency] for a long time and I've had a lot of support, but then they had to make a situation where they couldn't support me anymore and that's a negative because after receiving three to four years support, it's hard not to receive it anymore" (P2).

\section{Discussion}

We need to do better ... There needs to be education in schools, advice for young women growing up in particular cultures who are more likely to face these situations. We need to stop waiting for things like this to happen. We need to listen to women and offer support each and every time. No woman is going to go to the police and cry wolf. My sister's death should have been the last of these crimes.

(Payzee Mahmod, sister of Banaz Mahmod, cited in Sophie Brown 2019: “What it's like to lose your sister in an honor killing")

This study explored the lived experiences of women who had sought professional support after they had suffered 'honour'-based abuse and violence. At the time of the study, the women were no longer at an immediate risk of abuse, but they continued to experience difficulties relating to a range of issues such as accommodation and finance. Interpretative phenomenological analysis, applied to focus group data, revealed three superordinate themes; vulnerability, organisational and agency support, and rules and restrictions. There were six sub-themes; fear of external organisations, racism, education, support from law enforcement, immigration status, and agency funding.

Women's vulnerability was exacerbated by an initial fear of external organisations and racism from the wider community. The fear of external organisations (such as law enforcement and social services) is consistent with previous research suggesting that service providers may be perceived as 'outsiders' who cannot be trusted (Afrouz et al. 2018). Further, research suggests that women of Pakistani origin in the UK may be reluctant to report domestic abuse because they fear that social services will remove their children (Chowbey 2016) and abusers may encourage this fear to maintain control over female victims and reduce support-seeking or disclosure. It has been reported that women are more confident seeking support from law enforcement when they feel entitled to this assistance (e.g., when they are in paid employment and pay taxes, Chowbey 2016). Hence, greater awareness of the support available to victims and the role of the police is required.

Women recovering from 'honour' abuse or violence may choose to be accommodated in a predominantly White area to avoid detection by extended family or community members. This may, however, increase the risk of racist abuse. In recent years, Western countries such as the UK have demonstrated an increase in right-wing popularism and racist rhetoric (Hogan and Haltinner 2015), particularly in the context of immigration and Islamophobia (Hopkins 2016) and women may be particularly vulnerable to racism if wearing visible cues to religious belief (Mason-Bish and Zempi 2019). In the present study, women reported being the target of racism from the wider community. This abuse may impact on women's confidence to seek help and subsequent recovery. For example, those who experience racism may be reluctant to engage with social services and feel more dependent on their own family and community, lowering the likelihood that they will leave the abusive situation. Women who experience racism after leaving the abusive situation receive less social support and may be at increased risk of poor mental and physical ill-health. Additional community-based interventions are, therefore, required to address prejudice and discrimination.

Women discussed the organisational and agency support they received, particularly education or skills-based support (such as language proficiency) and their positive experiences of law enforcement. Previous research indicates that education can reduce women's vulnerability to domestic abuse (Oyewuwo-Gassikia 2016). For example, educated women are more likely to be aware of their legal 
rights and the presence of support services (Ahmad et al. 2009) while language proficiency may be a significant barrier to women wishing to disclose domestic abuse (Raj and Silverman 2007). In addition, education may promote recovery. For example, educated women are also more equipped to obtain paid employment and become self-sufficient. Hence, more proactive and extensive education or skills-based support would be a beneficial and a productive source of investment.

Victims of 'honour'-based abuse (though initially apprehensive) reported positive experiences of law enforcement. This is not consistent with previous reports indicating that police and social services are poor at supporting victims (Idriss 2018) but is compatible with prior reports that victims of 'honour'-based violence recognise the speed of police response in the UK when there is an immediate danger (Mulvihill et al. 2019). Future research should further investigate those factors which impact on police responses to 'honour'-based violence. For example, police may be reluctant to recognise the role of female perpetrators though women are more involved in the perpetration of 'honour'-based abuse than other forms of domestic abuse (Aplin 2016; Bates 2018; Khan 2018).

Though women commented on the positive support that they had received, they were conscious of those rules and restrictions that impacted on their care. In particular, women experiencing 'honour'-based abuse were conscious of their immigration status and the impact of this on their ability to secure protection or support. These accounts are consistent with previous research documenting the relationship between immigration status and the incidence or disclosure of domestic abuse (Afrouz et al. 2018; Raj and Silverman 2007). As discussed in one study "Families have told them if you leave, if you do tell anyone, we will send you back." (Burman and Chantler 2005, p. 66). Further research is required to determine the extent to which immigration increases the risk of abuse or perhaps forms part of the abuse. For example, studies indicate that partners and family members can exacerbate women's fears that they are at risk of deportation or not entitled to support (Ammar et al. 2013; Erez 2000; Mirza 2016). It is essential, therefore, that those providing support to women are conscious of these fears and provide the appropriate legal and practical support.

Women strongly endorsed the support received from non-government agencies but were conscious that agencies were limited by the funding available. Indeed, non-government agencies providing domestic abuse-based support to the South Asian community are typically dependent on private donations and fund raising (Merchant 2000). Funding issues impact on both the extent to which agencies can plan long-term support and the number of women they may assist. In the U.K., victims of 'honour'-based abuse are defined as 'priority groups' according to the Code of Practice for Victims of Crime (also referred to as the Victim's Code of Practice or VCOP) (Gill et al. 2018) and should receive enhanced support. Additional funding is, therefore, required to ensure that this assistance is available.

\section{Limitations and Future Research}

The present study recruited a small sample of women who had experienced 'honour'-based abuse and were of South Asian and Arab heritage. Though this allows a more in-depth assessment of each woman's experience, the ability to generalise findings is, of course, restricted. It is important to note, for example, that this bleak picture of gender inequality and domestic abuse is certainly not unique to collectivist cultures or specific countries. The recently published gender social norm index (United Nations Development Programme 2020) analysed data from 75 countries, which represents $80 \%$ of the world's population. This showed that nine out of ten people in these nations were biased against women, nearly one-third of whom thought it acceptable for a wife to be beaten by her husband.

Reflecting on the sensitive nature of the subject area and (though women were no longer in immediate risk from their partner or family) concerns over women's safety, interviews were not recorded, and quotations reflect detailed notes made by the researcher during the interview. Future research may wish to record such discussions. Further, studies would benefit from a more complete record of participant's demographic information. Factors such as the presence of children and specific ethnic or cultural background may impact on women's experiences of 'honour'-based abuse and engagement with support agencies and subsequent studies should investigate these. Finally, 
longitudinal research is required to determine the extent to which engagement with support agencies impacts on women's long-term health and wellbeing.

To conclude, the current study investigated the lived experiences of women who have suffered 'honour'-based abuse and sought professional support. Interpretative phenomenological analysis, applied to focus group data, revealed three superordinate themes; vulnerability, organisational and agency support, and rules and restrictions. There were six sub-themes; fear of external organisations, racism, education, support from law enforcement, immigration status, and agency reliance on public funds. Findings highlight the extent to which wider financial, legal, and social issues (e.g., immigration status and racism) impact on women's experience and the good practices (e.g., educational initiatives) that facilitate recovery and emancipation.

Author Contributions: Conceptualization, R.B. and R.K.; methodology, R.B.; formal analysis, G.B. and R.B.; investigation, R.B.; resources, R.B., R.K., and B.H.; data curation, R.B. and G.B.; writing-original draft preparation, R.B., R.K. and B.H.; writing-review and editing, R.K. and B.H.; supervision, R.K.; project administration, R.K. All authors have read and agreed to the published version of the manuscript.

Funding: This research received no external funding.

Acknowledgments: We are indebted to the courageous women who gave their time to speak to us about their experiences of 'honour' abuse, Thank you for your insight and generosity.

Conflicts of Interest: The authors declare no conflict of interest.

\section{References}

Abu-Lughod, Lila. 2016. Veiled Sentiments: Honor and Poetry in a Bedouin Society. Berkeley: University of California Press. Afrouz, Rojan, Beth R. Crisp, and Ann Taket. 2018. Seeking help in domestic violence among Muslim women in Muslim-majority and non-Muslim-majority countries: A literature review. Trauma, Violence, $\mathcal{E}$ Abuse.

Ahmad, Farah, Natasha Driver, Mary Jane McNally, and Donna E. Stewart. 2009. “Why doesn't she seek help for partner abuse?" An exploratory study with South Asian immigrant women. Social Science E Medicine 69: 613-22.

Al Gharaibeh, Fakir M. 2016. Debating the role of custom, religion and law in 'honour' crimes: Implications for social work. Ethics and Social Welfare 10: 122-39. [CrossRef]

Almeida, Rhea V., and Ken Dolan-Delvecchio. 1999. Addressing culture in batterers intervention: The Asian Indian community as an illustrative example. Violence Against Women 5: 654-83. [CrossRef]

Ammar, Nawal, Amanda Couture-Carron, Shahid Alvi, and Jaclyn San Antonio. 2013. Experiences of Muslim and non-Muslim battered immigrant women with the police in the United States: A closer understanding of commonalities and differences. Violence Against Women 19: 1449-71. [CrossRef] [PubMed]

Andersson, Neil, Anne Cockcroft, Umaira Ansari, Khalid Omer, Noor M. Ansari, Amir Khan, and Ubaid Ullah Chaudhry. 2010. Barriers to disclosing and reporting violence among women in Pakistan: Findings from a national household survey and focus group discussions. Journal of Interpersonal Violence 25: 1965-85. [CrossRef]

Aplin, Rachael. 2016. Exploring the role of mothers in 'honour' based abuse perpetration and the impact on the policing response. Women's Studies International Forum 60: 1-10. [CrossRef]

Bates, Lis. 2018. Female perpetrators of honour-based violence: Conspirators, collaborators, coerced? Journal of Aggression, Conflict and Peace Research 10: 293-303. [CrossRef]

Brown, Sophie. 2019. What It's Like to Lose Your Sister in an Honor Killing. Vice. April 25. Available online: https://www.vice.com/en_us/article/3k3z7j/banaz-mahmod-honor-killing-uk-police-failure (accessed on 11 March 2020).

Burman, Erica, and Khatidja Chantler. 2005. Domestic violence and minoritisation: Legal and policy barriers facing minoritized women leaving violent relationships. International Journal of Law and Psychiatry 28: 59-74. [CrossRef]

Chowbey, Punita. 2016. Employment, masculinities, and domestic violence in 'fragile'contexts: Pakistani women in Pakistan and the UK. Gender E Development 24: 493-509. [CrossRef]

Cohen, Dov, and Richard E. Nisbett. 1994. Self-protection and the culture of honor: Explaining southern violence. Personality and Social Psychology Bulletin 20: 551-67. [CrossRef] 
Cooney, Mark. 2014. Death by family: Honor violence as punishment. Punishment $\mathcal{E}$ Society 16: 406-27.

Darwish, Abdel-Fattah E., and Günter L. Huber. 2003. Individualism vs collectivism in different cultures: A cross-cultural study. Intercultural Education 14: 47-56. [CrossRef]

De Visser, Richard O., and Jonathan A. Smith. 2007. Alcohol consumption and masculine identity among young men. Psychology and Health 22: 595-614. [CrossRef]

dos Ventos Lopes Heimer, Rosa. 2019. A House Not a Home. The Housing Experiences of Black and Minoritised Women Survivors of Gender-Based Violence in London. Available online: https://trustforlondon. fra1.digitaloceanspaces.com/media/documents/WAHA_-_A_Roof_Not_A_Home_Report.pdf (accessed on 11 March 2020).

Dunne, Elizabeth A., and Ethel Quayle. 2001. The impact of iatrogenically acquired hepatitis C infection on the well-being and relationships of a group of Irish women. Journal of Health Psychology 6: 679-92. [CrossRef] [PubMed]

Dyer, Emily. 2015. Honour Killings in the UK. London: Henry Jackson Society, Available online: http://henryjacksonsociety. org/wp-content/uploads/2015/01/Honour-Killings-in-the-UK.pdf (accessed on 11 March 2020).

Erez, Edna. 2000. Immigration, culture conflict and domestic violence/woman battering. Crime Prevention and Community Safety 2: 27-36. [CrossRef]

Eshareturi, Cyril, Lyle Christine, and Morgan Angela. 2014. Policy responses to honor-based violence: A cultural or national problem? Journal of Aggression, Maltreatment E Trauma 23: 369-82.

Fatima, Huda, Tooba F. Qadir, Syed A. Hussain, and Ritesh G. Menezes. 2017. Pakistan steps up to remove "honour" from honour killing. The Lancet Global Health 5: 145. [CrossRef]

Flowers, Paul, Barbara Duncan, and Christina Knussen. 2003. Re-appraising HIV testing: An exploration of the psychosocial costs and benefits associated with learning one's HIV status in a purposive sample of Scottish gay men. British Journal of Health Psychology 8: 179-94. [CrossRef]

Forte, Alberto, Federico Trobia, Flavia Gualtieri, Dorian A. Lamis, Giuseppe Cardamone, Vincenzo Giallonardo, Andrea Fiorillo, Paolo Girardi, and Maurizio Pompili. 2018. Suicide risk among immigrants and ethnic minorities: A literature overview. International Journal of Environmental Research and Public Health 15: 1438. [CrossRef]

Fugate, Michelle, Leslie Landis, Kim Riordan, Sara Naureckas, and Barbara Engel. 2005. Barriers to domestic violence help seeking: Implications for intervention. Violence Against Women 11: 290-310. [CrossRef] [PubMed]

Galanti, Geri-Ann. 2003. The Hispanic family and male-female relationships: An overview. Journal of Transcultural Nursing 14: 180-85. [CrossRef]

Gengler, Justin J., Mariam F. Alkazemi, and Alanoud Alsharekh. 2018. Who supports honor-based violence in the Middle East? Findings from a national survey of Kuwait. Journal of Interpersonal Violence.

Gill, Aisha. 2008. 'Crimes of Honour' and Violence against Women in the UK. International Journal of Comparative and Applied Criminal Justice 32: 243-63. [CrossRef]

Gill, Aisha K., Pamela Cox, and Ruth Weir. 2018. Shaping Priority Services for UK Victims of Honour-Based Violence/Abuse, Forced Marriage, and Female Genital Mutilation. The Howard Journal of Crime and Justice 57: 576-95. [CrossRef]

Hague, Gill, Aisha K. Gill, and Nazand Begikhani. 2013. 'Honour'-based violence and Kurdish communities: Moving towards action and change in Iraqi Kurdistan and the UK. Journal of Gender Studies 22: 383-96. [CrossRef]

Her Majesty's Inspectorate of Constabulary (HMIC). 2015. The Depths of Dishonour: Hidden Voices and Shameful Crimes. An Inspection of the Police Response to Honour-Based Violence, Forced Marriage and Female Genital Mutilation; London: TSO.

Hicks, Madelyn Hsiao-Rei, and Dinesh Bhugra. 2003. Perceived causes of suicide attempts by UK South Asian women. American Journal of Orthopsychiatry 73: 455-62. [CrossRef]

Hogan, Jackie, and Kristin Haltinner. 2015. Floods, invaders, and parasites: Immigration threat narratives and right-wing populism in the USA, UK and Australia. Journal of Intercultural Studies 36: 520-43. [CrossRef]

Hopkins, Peter. 2016. Gendering Islamophobia, racism and white supremacy: Gendered violence against those who look Muslim. Dialogues in Human Geography 6: 186-89. [CrossRef] 
Husain, Nusrat, Nasim Chaudhry, Steevart V. Durairaj, Imran Chaudhry, Sarah Khan, Meher Husain, Diwaker Nagaraj, Farooq Naeem, and Waquas Waheed. 2011. Prevention of self-harm in British South Asian women: Study protocol of an exploratory RCT of culturally adapted manual assisted Problem Solving Training (C-MAP). Trials 12: 159. [CrossRef] [PubMed]

Idriss, Mohammad Mazher. 2018. Key agent and survivor recommendations for intervention in honour-based violence in the UK. International Journal of Comparative and Applied Criminal Justice 42: 321-39. [CrossRef]

Khan, Roxanne. 2018. Attitudes towards 'honor'violence and killings in collectivist cultures: Gender differences in Middle Eastern, North African, South Asian (MENASA) and Turkish populations. In The Routledge International Handbook of Human Aggression. Abingdon: Routledge, pp. 216-26.

Khan, Roxanne, and Beth Hall. 2020. Harmful Traditional Practices in the Workplace: Guidance for Best Practice. Preston: Honour Abuse Research Matrix, University of Central Lancashire, UK, Available online: https://clok.uclan.ac.uk/32803/7/32803\%20Harmful\%20Traditional\%20Practices\%20in\% 20the\%20Workplace\%20-\%20Guidance\%20for\%20Best\%20Practice\%202020.pdf (accessed on 11 April 2020).

Khan, Roxanne, Shamam Saleem, and Michelle Lowe. 2018. "Honour"-based violence in a British South Asian community. Safer Communities. [CrossRef]

Khan, Roxanne, Kumari Meena, and Adisa Olumide. 2020. Home Secretary-Open Letter: Hidden Harm Summit for Domestic Abuse 21 May 2020 COVID-19 Impact. Available online: http://clok.uclan.ac.uk/33372/1/Home\%20Secretary.\%20Open\%20Letter_\%20Hidden\%20Harm\%20Summit\% 20for\%20Domestic\%20Abuse\%2021st\%20May\%202020\%20\%28003\%29.pdf (accessed on 15 June 2020).

Kitzinger, Jenny. 1995. Qualitative Research: Introducing focus groups. BMJ: British Medical Journal 311: $299-302$. [CrossRef] [PubMed]

Lowe, Michelle, Roxanne Khan, Vanlal Thanzami, Mahsa Barzy, and Rozina Karmaliani. 2018. Attitudes toward intimate partner "honor"-based violence in India, Iran, Malaysia and Pakistan. Journal of Aggression, Conflict and Peace Research 10: 283-92. [CrossRef]

Madriz, Esther. 2000. Focus Groups in Feminist Research. In Handbook of Qualitative Research, 2nd ed. Edited by N. K. Denzin and Y. S. Lincoln. Thousand Oaks: Sage Publications, pp. 835-50.

Mason-Bish, Hannah, and Irene Zempi. 2019. Misogyny, racism, and Islamophobia: Street harassment at the intersections. Feminist Criminology 14: 540-59. [CrossRef]

McKenzie, Kwame, Kamaldeep Bhui, Kiran Nanchahal, and Bob Blizard. 2008. Suicide rates in people of South Asian origin in England and Wales: 1993-2003. The British Journal of Psychiatry 193: 406-9. [CrossRef]

Meetoo, Veena, and Heidi Safia Mirza. 2010. "There is nothing 'honourable'about honour killings": Gender, violence and the limits of multiculturalism. In Honour, Violence, Women and Islam. Abingdon: Routledge-Cavendish, pp. 50-74.

Merchant, Munira. 2000. A comparative study of agencies assisting domestic violence victims: Does the South Asian community have special needs? Journal of Social Distress and the Homeless 9: 249-59. [CrossRef]

Mirza, Nughmana. 2016. The UK government's conflicting agendas and 'harmful' immigration policies: Shaping South Asian women's experiences of abuse and 'exit'. Critical Social Policy 36: 592-609. [CrossRef]

Mulvihill, Natasha, Geetanjali Gangoli, Aisha K. Gill, and Marianne Hester. 2019. The experience of interactional justice for victims of 'honour'-based violence and abuse reporting to the police in England and Wales. Policing and Society 29: 640-56. [CrossRef]

Office for National Statistics. 2019. Population of England and Wales; London: Cabinet Office.

Oyewuwo-Gassikia, Olubunmi Basirat. 2016. American Muslim women and domestic violence service seeking: A literature review. Affilia 31: 450-62. [CrossRef]

Patel, Vikram, Chinthanie Ramasundarahettige, Lakshmi Vijayakumar, J. S. Thakur, Vendhan Gajalakshmi, Gopalkrishna Gururaj, Wilson Suraweera, Prabhat Jha, and Million Death Study Collaborators. 2012. Suicide mortality in India: A nationally representative survey. The Lancet 379: 2343-51. [CrossRef]

Race, Kathryn E. H., Deborah F. Hotch, and Todd Packer. 1994. Rehabilitation program evaluation: Use of focus groups to empower clients. Evaluation Review 18: 730-40. [CrossRef]

Rafferty, Yvonne. 2013. International dimensions of discrimination and violence against girls: A human rights perspective. Journal of International Women's Studies 14: 1-23.

Raj, Anita, and Jay G. Silverman. 2007. Domestic violence help-seeking behaviors of South Asian battered women residing in the United States. International Review of Victimology 14: 143-70. [CrossRef] 
Schatzman, Leonard, and Anselm Leonard Strauss. 1973. Field Research: Strategies for a Natural Sociology. Upper Saddle River: Prentice Hall.

Sharma, Saachi. 2017. NCRB data shows 95\% rape victims in India known to offenders; Madhya Pradesh tops the list. First Post. May 9. Available online: https://www.firstpost.com/india/ncrb-data-shows-95-rape-victimsin-india-known-to-offenders-3433136.html (accessed on 11 March 2020).

Smith, Jonathan A., Paul Flowers, and Michael Larkin. 2009. Interpretative Phenomenological Analysis: Theory, Method and Research. Thousand Oaks: SAGE Publications.

United Nations Children's Fund (UNICEF). 2014. Hidden in Plain Sight: A Statistical Analysis of Violence against Children. New York: UNICEF.

United Nations Development Programme. 2020. Tackling Social Norms: A Game Changer for Gender Inequalities. New York: United Nations Development Programme.

Vandello, Joseph. 2016. Do we need a psychology of women in the Islamic world? Sex Roles 75: 623-29. [CrossRef] Vandello, Joseph A., and Dov Cohen. 2003. Male honor and female fidelity: Implicit cultural scripts that perpetuate domestic violence. Journal of Personality and Social Psychology 84: 997. [CrossRef] [PubMed]

(C) 2020 by the authors. Licensee MDPI, Basel, Switzerland. This article is an open access article distributed under the terms and conditions of the Creative Commons Attribution (CC BY) license (http://creativecommons.org/licenses/by/4.0/). 